\title{
Optimization of Electricity Consumption in a building
}

\author{
Kahina LOUADJ ${ }^{1,4}$, Fethi DEMIM ${ }^{2}$, Abdelkrim NEMRA ${ }^{2}$, Mohamed AIDENE ${ }^{3}$ \\ Philippe MARTHON ${ }^{4}$ and Hocine IDDIR ${ }^{5}$
}

\begin{abstract}
The main objective of an energy regulation of a building is to maintain internal thermal comfort, as well as minimize energy consumption, or reduce the peak of electrical consumption. The dynamic programming has been used to minimize a cost function, accounting for a high peak electricity tariff, under constraints related to comfort (minimal temperature, maximal temperature variation) and the maximum heating power. The proposed energy management consists in over-heating the building during the hours before the peak knowing in advance the weather, occupation and internal gains for the day. The method has been tested in a case study corresponding to a house of a four-person family with performance levels: high construction and poorly insulated old house.
\end{abstract}

\section{INTRODUCTION}

At the global level, energy demand is a tendency for high increase. As a result of population growth and economic growth, driven mainly by emerging countries, especially China and India take into account its demographics, its could to double by 2050. These countries, especially the big four emerging markets, which are BASIC [9] (Brazil, South Africa, India and China), but also those in the Middle East, far more than the OECD countries (Organization for Economic Cooperation and Development) [9], " energy markets and prices that will become more and more high. Fossil energies, first and foremost oil, now insure more than $80 \%$ of the supply. This situation marks the global dependence on Carbon energies and pose the question of its holding up, both environmentally and in terms of supply of raw materials. If global reserves fossil fuels appear abundant in terms of future needs, conditions of their access are increasingly difficult: the investments in infrastructure needed for the use of resources are massive and the geopolitical context is inherently uncertain. The climatic constraint change should also appear earlier than the geopolitics.

At European level, the dynamic is different, especially since population growth and economic growth are weaker, but it is still dependent on the rest of the world energetically, to try to achieve self-sufficiency or energetic mastery the European

*K.Louadj, F.Demim, A.Nemra, M.Aidene, P.Marthon, H.Iddir

${ }^{1}$ Université de Bouira. Département de Mathématiques. Bouira. Algérie. louadj kahina@yahoo.fr

2 Laboratoire Robotique et Productique, Ecole Militaire Polytechnique, Bordj El Bahri,BP 17, 16111, Alger. Algérie. demifethi@gmail.com, karim nemra@yahoo.fr

3 Laboratoire de Conception et Conduites Systèmes de Production (L2CSP). Tizi-Ouzou, Algérie. aidene@mail.ummto.dz

4 IRIT-ENSEEIHT. Toulouse, France. Philippe. Marthondenseeiht. fr

${ }^{5}$ Université Mouloud Mammeri. Département de Mathématiques. TiziOuzou. Algérie. iddir.hocine@hotmail.fr
Union has implemented the pact " Energy-Climate", which sets 2020 binding objectives [6], [7], [8].

Two countries have carried out such Germany and the United Kingdom forward-looking exercises. Germany has made the exit from its priority as a result of the Fukushima accident. His program energy (Energiekonzept) [9], prior to the events in Fukushima, was already based on the goal of halving demand 2050.

The United Kingdom is developing an approach based on a broad portfolio of low carbon technologies, including without a priori renewable energies, nuclear power and CCS (capture and carbon storage), with a view to technological neutrality and optimum economic.

The energy situation in Algeria involves three challenges: diversify forms of energy, increase energy efficiency and give room for maneuver. What we are most interested in our work is the concept of energy efficiency.

In Algeria, the housing sector consumes more than half of national electricity production, which encourages the government to take regulatory measures such as the elimination of electricity consumption, construction of low consumption or passive buildings and renovation old build which ensures the comfort, reduces the invoice energy, creates employment, reduces greenhouse gas emissions and avoids spikes in consumption that exceeds production capacity nationally.

Dynamic programming which is a branch in an Operational research, provides us with sequential optimization algorithms necessary for the modeling of problems in the field of energy. Our work is summarized in the study of an optimal the elimination of peak power consumption in a building by the application of dynamic programming [3], [19].

The Bellman equation, also known as the Hamilton-JacobiBellman equation (HJB), is a result of the method of dynamic programming initiated by Richard Bellman in the 1950 s to solve optimization problems. Ie problems where the best possible decisions must be made on each date for a given performance criterion. The equation of dynamic programming generalizes William Hamilton-JacobiBellman's previous classical mechanics in recognition of the contribution of these three great scientific personalities. Historically applied in engineering and then in other fields of applied mathematics, the HJB equation has become an important tool in decision-making problems in economics and finance [3], [14], [19].

The article is divided into four sections, The first section, we gives us an overview of Bellman's optimality principle, Bellman equation and application to the optimal control. And 
after, formulate the problem to minimize the cost of the electricity energy in the second section. In the third section, a practical example of a house of family of four persons under thermal simulation and the design of an application that optimizes the heating and the elimination of power consumption during peak periods daily. Finally, we achieve by the results which are founded by the software $\mathrm{C}++$ and conclusion is provided.

\section{Optimization Algorithm}

The dynamic programming algorithm is a sequential optimization algorithm for obtaining the overall optimum by scanning all the possible solutions, in this case, it is a question by determining a set of controls (heating on or off) Making it's possible to minimize the cost function over the period considered. Let be noted $u$ the control variable including $N_{c}$ dimensions:

$$
u(t)=u_{t} \in U, \quad U \subset \mathbf{R}^{m}
$$

with $U_{t}$ all the possible commands.

The state equation at each time step $t$ is then:

$$
x(t)=x_{t}, \quad x(t+1)=f(x(t), u(t), t)
$$

where $x$ is the temporally discretized state variable

$$
x(t)=x_{t} \in X_{t}, \quad X_{t} \subset \mathbf{R}^{n}
$$

the value function $v_{t}$ corresponding to the passage cost is defined as:

$$
v_{t}\left(x_{t}, x_{t+1}\right), \quad x_{t+1} \in \Gamma_{t}\left(x_{t}\right)
$$

$\Gamma_{t}$ is the set of possible states at $t$, the cost function is the sum of the values of functions on all time steps.

$$
V_{0}^{t}=\sum_{j=0}^{t-1} v_{j}\left(x_{j}, x_{j+1}\right)
$$

The optimization seeks to minimize the following objective function on $N$ steps:

$$
J=\operatorname{Min}\left[V_{N}\right]
$$

This equation is the set of commands to go from $x_{0}$ to $x_{1}$. The optimization times can be long. Equation (6) then becomes:

$$
J=\operatorname{Min}\left[V_{0}^{N-1}\right]=\operatorname{Min}\left(v_{0}\left(x_{0}, x_{1}\right)\right)+\operatorname{Min}\left[V_{1}^{N-1}\right]
$$

The objective is to find the set of commands $U=$ $\left(u_{1}, u_{2}, \ldots, u_{N}\right)$ minimizing (7) with constraints on state variable (3) and control (1).

\section{A. Optimality Principle's}

The dynamic programming is based on a technique that Bellman called "Principle of Optimality". This general principle states that the solution of a global problem can be obtained by decomposing the problem into sub problems easier to solve.

\section{Mathematical Modeling}

The aim of mathematical modeling and finding the set of commands $U=\left(u_{1}, u_{2}, \ldots, u_{N}\right)$ which optimizes the cumulative cost over a given time interval $t \in[1, N]$. Let be consider the following constraints:

$$
\begin{aligned}
& \left\{\begin{array}{l}
u(t)=u_{t}, \\
x(t)=x_{t}, \\
x(t+1)=f\left(x_{t}, u_{t}, t\right),
\end{array}\right. \\
& V_{t}\left(x_{t}, u_{t}\right) \\
& V_{1}^{t}=\sum_{j=1}^{t} V_{j}\left(x_{t}, x_{t+1}\right), \\
& F=\min \left[V_{1}^{N}\right]
\end{aligned}
$$

- $t$ : Time.

- $u(t)$ : Control of the system (increase in temperature of $\left.x_{t}, x_{t+1}\right)$.

- $x(t)$ : State of the system (temperatures in step $t$ ).

- $V_{t}$ : Cost passage of $x_{t}$ to $x_{t+1}$.

- $V_{1}^{t}$ : Cumulative cost of $j=1$ to $j=t$.

- $F$ : The performance.

The objective is to optimize the heating cost of the day and maintain the internal comfort at a temperature of $19^{\circ}$ Minimum and a temperature change of $2^{\circ}$ Maximum per hour.

\section{A. Program under $C++$ :}

The following program allows us to enter data concerning the building's energy environment. Gives the cumulative cost for one day as well as the order $U$.

- Minimum temperature of building $19^{\circ}$.

- Maximum temperature of building $25^{\circ}$.

- The variation is less than or equal to $2^{\circ} /$ hour.

- The fall in temperature in a supposedly isolated house $1^{\circ}$.

- The drop in temperature in a less isolated house $2^{\circ}$.

- The Cost of heating power to increase the temperature of $1^{\circ}$ is given in Table 1 :

\section{TABLE I}

$\begin{array}{ll}\text { Off Hours: } 1 h \rightarrow 8 h & 8 \mathrm{DA} \\ \text { Full Hours: } 9 h \rightarrow 16 h, 22 h \rightarrow \text { midnight } & 12 \mathrm{~h} \\ \text { Peak Hours: } 17 h \rightarrow 21 h & 25 \mathrm{~h}\end{array}$

\section{B. The performance:}

The performance is defined as follows:

$$
F=\min \left[V_{1}^{N}\right]
$$

Where

$V_{1}^{N}=\sum_{t+1}^{N}\left(u_{t}+\beta\right) * G, u_{t}=x_{t+1}-x_{t}, t=1, \ldots, N+$ 1. $\left(x_{1}=x_{N+1}\right)$,

$G=P r_{t} * W$.

- $\beta$ : The step represents the temperature drop per hour (heating off). 
TABLE II

CUMULATIVE COST WITHOUT ERASING ELECTRICITY CONSUMPTION IN A WELL INSULATED BUILDING

$\begin{array}{llllll}\begin{array}{l}\text { Hours } \\ \text { (t) }\end{array} & \begin{array}{l}\text { Temperature } \\ \left(X_{t}\right)\end{array} & U & \begin{array}{l}\text { The } \\ \text { step }\end{array} & \begin{array}{l}\text { Cost } \\ (\mathrm{DA})\end{array} & \begin{array}{l}\text { Cumulative } \\ \text { Cost } V_{t}\end{array} \\ 1 & 19 & \mathbf{0} & 1 & 8 & \mathbf{8} \\ 2 & 19 & \mathbf{0} & 1 & 8 & \mathbf{8} \\ 3 & 19 & \mathbf{0} & 1 & 8 & \mathbf{8} \\ 4 & 19 & \mathbf{0} & 1 & 8 & \mathbf{8} \\ 5 & 19 & \mathbf{0} & 1 & 8 & \mathbf{8} \\ 6 & 19 & \mathbf{0} & 1 & 8 & \mathbf{8} \\ 7 & 19 & \mathbf{0} & 1 & 8 & \mathbf{8} \\ 8 & 19 & \mathbf{0} & 1 & 8 & \mathbf{8} \\ 9 & 19 & \mathbf{0} & 1 & 12 & \mathbf{1 2} \\ 10 & 19 & \mathbf{0} & 1 & 12 & \mathbf{1 2} \\ 11 & 19 & \mathbf{0} & 1 & 12 & \mathbf{1 2} \\ 12 & 19 & \mathbf{0} & 1 & 12 & \mathbf{1 2} \\ 13 & 19 & \mathbf{0} & 1 & 12 & \mathbf{1 2} \\ 14 & 19 & \mathbf{0} & 1 & 12 & \mathbf{1 2} \\ 15 & 19 & \mathbf{0} & 1 & 12 & \mathbf{1 2} \\ 16 & 19 & \mathbf{0} & 1 & 12 & \mathbf{1 2} \\ 17 & 19 & \mathbf{0} & 1 & 25 & \mathbf{2 5} \\ 18 & 19 & \mathbf{0} & 1 & 25 & \mathbf{2 5} \\ 19 & 19 & \mathbf{0} & 1 & 25 & \mathbf{2 5} \\ 20 & 19 & \mathbf{0} & 1 & 25 & \mathbf{2 5} \\ 21 & 19 & \mathbf{0} & 1 & 25 & \mathbf{2 5} \\ 22 & 19 & \mathbf{0} & 1 & 12 & \mathbf{1 2} \\ 23 & 19 & \mathbf{0} & 1 & 12 & \mathbf{1 2} \\ 24 & 19 & \mathbf{0} & 1 & 12 & \mathbf{1 2} \\ 25 & 19 & & & & \\ \text { Total } & & & & & 321 \\ \text { F(DA) } & & & & & \\ & & & & & \end{array}$

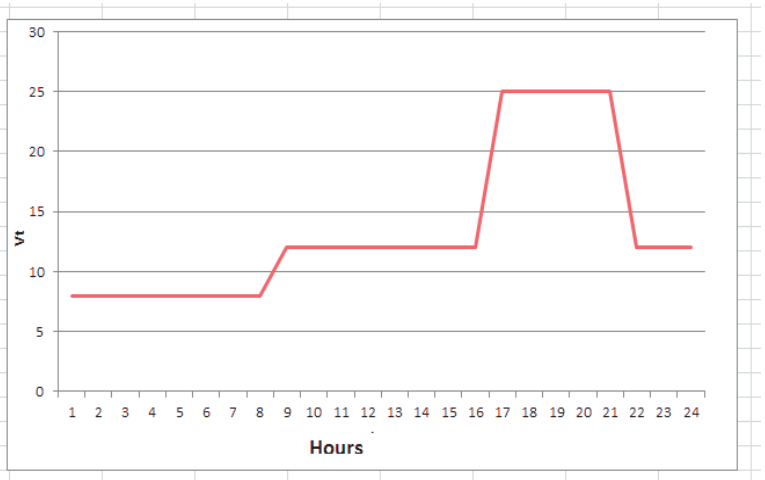

Fig. 1. Cumulative cost without erasing electricity consumption in a well insulated building

- $P r_{t}$ :The cost of using the electricity in KWh between $t$ and $t+1$.

- $W$ : Heating power $\left(+1^{\circ}\right)$.

\section{Simulation results(cumulative cost)}

The results of the execution of the previous program can be summarized in the following tables:

Tables of Cumulative of the objective function: Synthesis: In a well insulated building: In the table $\mathrm{V}$, a profit of $26 \%$ was realized with an erasure of $5 / 5$ of the peak hours and $5 / 11$ of the full hours. In a poorly insulated building:

In the table VI, a profit of $13 \%$ was realized with an erasure of $3 / 5$ of the peak hours and $3 / 11$ of the full hours.
Algorithm 1 Program (Cumulative Cost)

\# include $<$ cstdlib $>$

\# include $<$ iostream $>$

using namespace std;

int main()

int i,b,n,a,f,p,pt,m,c,o,x,temp[24],price[24],pcum;

$\operatorname{cost}<<" \backslash n "$;

$\operatorname{cost}<<" \backslash n "$;

cost $<<" \backslash n * * * * * * *$ The cumulative cost for one day $* * * * * * * * * * * * * *$;

$\operatorname{cost}<<" \backslash n "$;

cost $<<" \backslash n$ the step is the fall of the temperature in degree per hour : "; $\operatorname{cost}<<" \backslash n "$;

$\operatorname{cost}<<" \backslash n-1$ Degree for well insulated building ";

$\operatorname{cost}<<" \backslash n "$

$\operatorname{cost}<<" \backslash n-2$ Degree for badly insulated building ";

$\operatorname{cost}<<" \backslash n "$

while $(n>0)$

$\operatorname{cost}<<" \backslash n$ do you want to seize you? If yes write 1 else

$0: " ; \operatorname{cin}>>\backslash n$;

if $(n==0)$ return EXIT SUCCESS;

cost $<<" \backslash n$ enter the step $[1,2]: " ; \operatorname{cin}>>b$;

cost $<<" \backslash n "$;

$\operatorname{cost}<<" \backslash n$ the cost of off temperature: "; $\operatorname{cin}>>c$;

$\cos \mathrm{t}<<" \backslash n "$;

$\operatorname{cost}<<" \backslash n$ The cost of full temperature: "; $\operatorname{cin}>>p$;

$\operatorname{cost}<<" \backslash n "$;

cost $<<" \backslash n$ the cost of the peak temperature: "; $\operatorname{cin}>>$ pt;

$\cos \mathrm{t}<<" \backslash n "$;

cost $<<" \backslash n$ enter the temperature ";

for $(i=1 ; i<9 ; i++) \quad \operatorname{cost}[\mathrm{i}]=\mathrm{c}$;

for $(i=9 ; i<17 ; i++) \operatorname{cost}[\mathrm{i}]=\mathrm{p}$;

for $(i=17 ; i<22 ; i++) \operatorname{cost}[\mathrm{i}]=\mathrm{pt}$;

for $(i=22 ; i<25 ; i++) \operatorname{cost}[\mathrm{i}]=\mathrm{p}$;

$\cos \mathrm{t}<<" \backslash n "$;

cost $<<" \backslash n$ For a classic control type without erasing enter 3 "; cost $<<" \backslash n "$;

cost $<<" \backslash n$ For a regulation type with erase enter 4 ";

$\operatorname{cost}<<" \backslash n "$;

cost $<<" \backslash n$ give the type "; $\operatorname{cin}>>f$;

if $(f==3)$ cost $<<$ " Gives the constant temperature in the building ";

$\operatorname{cin}>>a$

for $(i=1 ; i<25 ; i++)$ temp $[\mathrm{i}]=\mathrm{a}$;

if $(f==4) \quad$ cost $<<" \backslash n$ give temperature minimum :

"; $\operatorname{cin}>>a$;

cost $<<" \backslash n$ give temperature $\max : "$; $\operatorname{cin}>>m ; \cos \mathrm{t}<<$ $" \backslash n "$;

for $(i=1 ; i<25 ; i++)$ if $(\operatorname{cost}[\mathrm{i}]-\operatorname{cost}[\mathrm{i}+1]>=p t-p$; $\mathrm{o}=\mathrm{i}+1$;

cost $<<" \backslash n$ Hour is : " $<<o<<" h "$; 
cost $<<" \backslash n$ the temperature a " $<<o<<" h$ est :"; $\cos \mathrm{t}<<a$;

for $(i=0 ; i<o ; i++) \operatorname{cost}<<" \backslash n$ enter the temperature $"<<o-i<<" h: "$

$\operatorname{cin}>>\operatorname{temp}[o-i]$;

$\operatorname{cost}<<" \backslash n "$;

for $(i=1 ; i<25-o ; i++) \quad$ cost $<<" \backslash n$ enter temperature " $<<25-i<<" h: "$;

$\operatorname{cin}>>\operatorname{temp}[25-i] ;$ for $(\mathrm{i}=1 ; \mathrm{i} ; 25 ; \mathrm{i}++) \cos \mathrm{t}<<" \backslash n$ the temperature " $<<i<<" h$ : "; cost $<<$ temp $[i]$;

temp[25]=temp[1];

pcum $=0$;

for $(i=1 ; i<25 ; i++) \quad$ pcum=pcum $+(\operatorname{temp}[\mathrm{i}+1]$ temp $[\mathrm{i}]+\mathrm{b}) * \operatorname{cost}[\mathrm{i}] ; \quad \cos \mathrm{t}<<" \backslash n "$;

cost $<<" \backslash n$ The cumulative cost for One day is : " $<<$ pcum $<<$ "Dinars";

cost $<<" \backslash n$ The control $U$ is ";

$\operatorname{cost}<<" \backslash n "$

for $(i=1 ; i<25 ; i++) \operatorname{cost}<<" \backslash n-U("<<i<<")$

$="<<\operatorname{temp}[i+1]-\operatorname{temp}[i]$

system("PAUSE");

return EXIT SUCCESS;

TABLE III

CUMULATIVE COST WITH ERASING OF ELECTRICITY CONSUMPTION IN A WELL INSULATED BUILDING

\begin{tabular}{|c|c|c|c|c|c|c|}
\hline $\begin{array}{l}\text { Hours } \\
\text { (t) }\end{array}$ & $\begin{array}{l}\text { Temperature } \\
\left(X_{t}\right)\end{array}$ & $U$ & $\begin{array}{l}\text { The } \\
\text { step } \\
(\beta)\end{array}$ & $\begin{array}{l}\text { Cost } \\
\text { (DA) }\end{array}$ & $\begin{array}{l}\text { Cumulative } \\
\operatorname{cost} V_{t}\end{array}$ & \\
\hline 1 & 19 & 0 & 1 & 8 & 8 & \\
\hline 2 & 19 & 1 & 1 & 8 & 16 & \\
\hline 3 & 20 & 1 & 1 & 8 & 16 & \\
\hline 4 & 21 & 1 & 1 & 8 & 16 & \\
\hline 5 & 22 & 1 & 1 & 8 & 16 & \\
\hline 6 & 23 & 1 & 1 & 8 & 16 & \\
\hline 7 & 24 & 1 & 1 & 8 & 16 & \\
\hline 8 & 25 & -1 & 1 & 8 & 0 & 1 \\
\hline 9 & 24 & -1 & 1 & 12 & 0 & 2 \\
\hline 10 & 23 & -1 & 1 & 12 & 0 & 3 \\
\hline 11 & 22 & -1 & 1 & 12 & 0 & 4 \\
\hline 12 & 21 & 1 & 1 & 12 & 24 & \\
\hline 13 & 22 & 1 & 1 & 12 & 24 & \\
\hline 14 & 23 & 1 & 1 & 12 & 24 & \\
\hline 15 & 24 & 1 & 1 & 12 & 24 & \\
\hline 16 & 25 & -1 & 1 & 12 & 0 & 1 \\
\hline 17 & 24 & -1 & 1 & 25 & 0 & 2 \\
\hline 18 & 23 & -1 & 1 & 25 & 0 & 3 \\
\hline 19 & 22 & -1 & 1 & 25 & 0 & 4 \\
\hline 20 & 21 & -1 & 1 & 25 & 0 & 5 \\
\hline 21 & 20 & -1 & 1 & 25 & 0 & 6 \\
\hline 22 & 19 & 0 & 1 & 12 & 12 & \\
\hline 23 & 19 & 0 & 1 & 12 & 12 & \\
\hline 24 & 19 & 0 & 1 & 12 & 12 & \\
\hline 25 & 19 & & & & & \\
\hline $\begin{array}{l}\text { Total } \\
\text { F } \\
\text { (DA) }\end{array}$ & & & & & 236 & \\
\hline
\end{tabular}

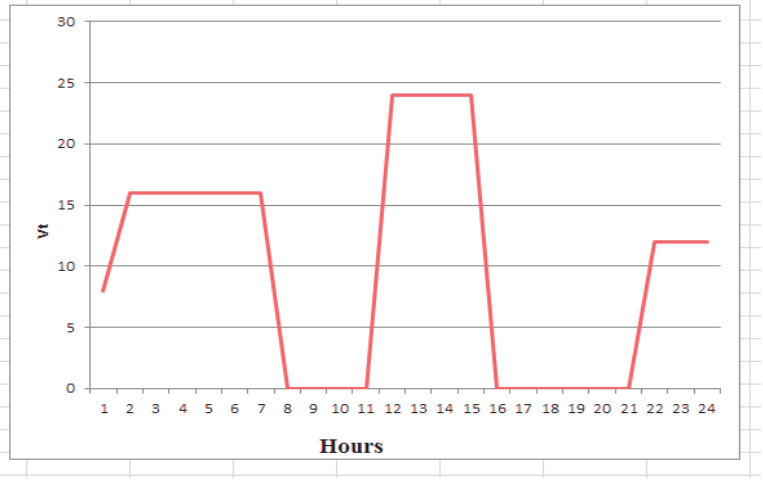

Fig. 2. Cumulative cost with erasing electricity consumption in a well insulated building

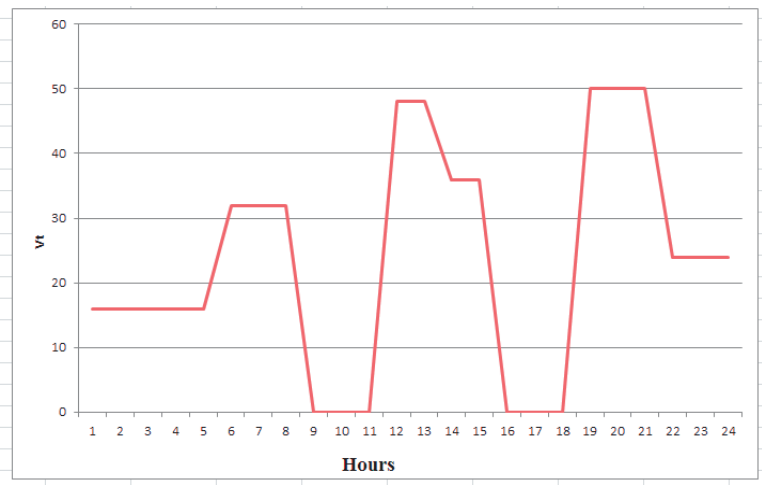

Fig. 3. Cumulative cost with elimination of electricity consumption in a poorly insulated building

From the preceding tables (V and IV), in a well-isolated house where the application of satisfactory results and a peak erase of $100 \%$, on the other hand in the poorly insulated house the result is not very effective see Figures 1, 2 and 3. In Conclusion,

The function value must not only eliminate the consumption of electricity during peak period but also to take into account the cost differential between off-peak hours and peak hours. The cumulative cost does not increase either during all or part of the full hours following the day. Optimal regulation heats the building mainly during off hours, and can clear up to $15 \mathrm{~h}$ in a row the heating consumption.

\section{CONCLUSION}

Optimization by the dynamic programming made to study an optimal energy management strategy of a building the heating was ordered to allow the erasure of its electricity consumption during the peak period going from $17 \mathrm{~h}$ to $21 \mathrm{~h}$ while maintaining the comfort inside the building. A case study on a low-energy building and another on a little isolated building showed that deletion of the tip is only possible on the house very well insulated.

Application of the sequential optimization algorithm has proved its effectiveness in optimizing dynamic problems. To obtain a result, one notices that the step plays a very interesting role, in the mechanism of optimization of the 
TABLE IV

CUMULATIVE COST WITH ERASING OF ELECTRICITY CONSUMPTION IN A POORLY INSULATED BUILDING

\begin{tabular}{|c|c|c|c|c|c|c|}
\hline $\begin{array}{l}\text { Hours } \\
\text { (t) }\end{array}$ & $\begin{array}{l}\text { Temperature } \\
\left(X_{t}\right)\end{array}$ & $U$ & $\begin{array}{l}\text { The } \\
\text { step } \\
(\beta)\end{array}$ & $\begin{array}{l}\text { Cost } \\
\text { (DA) }\end{array}$ & $\begin{array}{l}\text { Cumulative } \\
\text { Cost } V_{t}\end{array}$ & \\
\hline 1 & 19 & 0 & 2 & 8 & 16 & \\
\hline 2 & 19 & 0 & 2 & 8 & 16 & \\
\hline 3 & 19 & 0 & 1 & 8 & 16 & \\
\hline 4 & 19 & 0 & 1 & 8 & 16 & \\
\hline 5 & 19 & 0 & 1 & 8 & 16 & \\
\hline 6 & 19 & 0 & 1 & 8 & 32 & \\
\hline 7 & 19 & 0 & 1 & 8 & 32 & \\
\hline 8 & 19 & 0 & 1 & 8 & 32 & \\
\hline 9 & 19 & 0 & 1 & 12 & 0 & 1 \\
\hline 10 & 19 & 0 & 1 & 12 & 0 & 2 \\
\hline 11 & 19 & 0 & 1 & 12 & 0 & 3 \\
\hline 12 & 19 & 0 & 1 & 12 & 48 & \\
\hline 13 & 19 & 0 & 1 & 12 & 48 & \\
\hline 14 & 19 & 0 & 1 & 12 & 36 & \\
\hline 15 & 19 & 0 & 1 & 12 & 36 & \\
\hline 16 & 19 & 0 & 1 & 12 & 0 & 1 \\
\hline 17 & 19 & 0 & 1 & 25 & 0 & 2 \\
\hline 18 & 19 & 0 & 1 & 25 & 0 & 3 \\
\hline 19 & 19 & 0 & 1 & 25 & 50 & \\
\hline 20 & 19 & 0 & 1 & 25 & 50 & \\
\hline 21 & 19 & 0 & 1 & 25 & 50 & \\
\hline 22 & 19 & 0 & 1 & 12 & 24 & \\
\hline 23 & 19 & 0 & 1 & 12 & 24 & \\
\hline 24 & 19 & 0 & 1 & 12 & 24 & \\
\hline 25 & 19 & & & & & \\
\hline $\begin{array}{l}\text { Total } \\
\text { F } \\
\text { (DA) }\end{array}$ & & & & & 566 & \\
\hline
\end{tabular}

TABLE V

$\begin{array}{lll}\text { Cost without erasing } & \text { Cost with erasing } & \text { Difference } \% \\ 321 \text { DA } & 236 \text { DA } & 26 \%\end{array}$

TABLE VI

$\begin{array}{lll}\text { Cost without erasing } & \text { Cost with erasing } & \text { Difference } \% \\ 642 \text { DA } & 556 \text { DA } & 13 \%\end{array}$

eradication of the peaks of electric consumption. The constraint of controlling energy storage in the building mass or the thermal insulation of buildings is a crucial necessity in the program of effacement of high consumption of electrical energy. As perspective, we can extended the study for a week, or a month and try to find solutions for the consumption of electrical energy.

\section{REFERENCES}

[1] Claude Mandil. Jacques Percebois. Rapport énérgie 2050 février 2012 Ministère Français de l'économie de finance et de l'industrie p 21-22. 2012.

[2] Bruno Peuportier, F. Berenger. Etude d'une stratégie d'effacement de la consommation électrique de pointe dans le bâtiment par l'application de la programmation dynamique, XXXe Rencontres AUGC-IBPSA Chambéry, Savoie, 6 au 8 juin 2012.

[3] Art Lew, H. Mauch, Dynamic programming a computational Tool. Springer pages 379. 2007.

[4] Aurélie Kaemmerlen. Transfert de chaleur à travers les isolants thermiques du bâtiment. Thèse de Doctorat, 2009.
[5] Didier Roux. L'efficacité énergétique des bâtiments: un défie stratégique. pages 81-92. Revue AGIR $\mathrm{N}^{\circ}=42,2013$.

[6] R. E. Bellman. Dynamic programming. Princeton University Press, Princeton, NJ, 1963.

[7] Braun J.E., Montgomery K.W., Chaturvedi N., Evaluating the Performance of Building Thermal Mass Control Strategies, HVACR Research, vol. 7, ${ }^{\circ} 4$, p. 403- 428,2001.

[8] Dounis A.I., Caraiscos C., Advanced control systems engineering for energy and comfort management in a building environment A review , Renewable and sustainable Energy Reviews, vol. 13, p.1246-1261, 2009.

[9] Oldewurtel F et al., Energy efficient building climate control using Stochastic Model Predictive Control and weather predictions, American Control Conference, Baltimore USA, 30 Juin - 2 Juillet, 2010.

[10] Peuportier B., Sommereux I.B., Simulation tool with its expert interface for the thermal design of multizone buildings, International Journal of Sustainable Energy, vol. 8, p 109-120, 1990.

[11] Sane H., Guay M., Minmax Dynamic Optimization over a Finite-time Horizon for Building Demand Control, American Control Conference, Seattle USA, 11-13 Juin, 2008.

[12] Tyagi, V.V., Buddhi, D., PCM thermal storage in buildings : A State of art., Renewable and sustainable Energy Reviews. vol. 11, p. 11461166, 2007.

[13] A. Ahmad, M. Hassan, M. Abdullah. A review on applications of ANN and SVM for building electrical energy consumption forecasting. Renewable and Sustainable Energy Reviews Elsevier 2014. Volume 33, May 2014, Pages 102-109, 2014.

[14] F. Demim, A.Nemra, K.Louadj. Solution of an optimal control problem of the robot with Bellman Principle's. Conférence Internationale en Sciences et Technologies Electriques, October 26-28, CISTEM'16, Morocco, Marakech, 2016.

[15] F.Demim, K.Louadj, M.Aidene, A. Nemra. Solution of an Optimal Control Problem with Vector Control using Relaxation Method, Automatic Control and System Engineering Journal, Volume 16, Issue 2, ISSN 1687-4811, ICGST LLC, Delaware, USA, 2016

[16] K.Louadj, P.Spitéri, M.Aidene, F.Messine. An optimal control problem with free final time for aircraft flight with wind. Colloque sur l'optimisation et les systèmes d'information (COSI 2014), Bejaia, 08/06/2014-10/06/2014.

[17] K.Louadj, P.Spitéri, M.Aidene, F.Messine. Optimal command for the control of the air navigation of an aircraft. The Second International Conference on Electrical Engineering and Control Applications, Constantine, 18/11/2014-20/11/2014.

[18] S.Titouche, P.Spiteri, F. Messine, M.Aidene. Optimal control of a large thermic, Journal Control System, Vol.25, pp.50-58, January 2015.

[19] F.Demim, A. Nemra, K.Louadj, M.Hamerlain. Simultaneous localization, mapping, and path planning for unmanned vehicle using optimal control, Advances in Mechanical Engineering, 2018, Vol. 10(1) 1-25. 